\title{
Correction to: Glycemic control of people with diabetes over months after the 2018 North Osaka Earthquake
}

\author{
Hirotaka Watanabe $^{1} \cdot$ Mitsuyoshi Takahara $^{1,2} \oplus \cdot$ Naoto Katakami $^{1,3} \cdot$ Taka-aki Matsuoka $^{1} \cdot$ lichiro Shimomura $^{1}$
}

Published online: 23 October 2021

(c) The Japan Diabetes Society 2021

Correction to: Diabetology International (2021) 12:80-86
https://doi.org/10.1007/s13340-020-00438-6

In the original publication of the article, under the Results section in the Abstract, the value of " $P$ for trend" was published incorrectly as ( $P$ for trend $=0.025$ ).

The correct value should read as $(P$ for trend $=0.031)$.

Publisher's Note Springer Nature remains neutral with regard to jurisdictional claims in published maps and institutional affiliations.

The original article can be found online at https://doi.org/10.1007/ s13340-020-00438-6.

Mitsuyoshi Takahara

takahara@endmet.med.osaka-u.ac.jp

1 Department of Metabolic Medicine, Osaka University Graduate School of Medicine, 2-2 Yamadaoka, Suita, Osaka 565-0871, Japan

2 Department of Diabetes Care Medicine, Osaka University Graduate School of Medicine, 2-2 Yamadaoka, Suita, Osaka 565-0871, Japan

3 Department of Atherosclerosis and Metabolism, Osaka University Graduate School of Medicine, 2-2 Yamadaoka, Suita, Osaka 565-0871, Japan 